\title{
Luiz Roberto Vialle (ed), Michael G. Fehlings, Norbert Weidner (guest eds): AOSpine masters series vol 7
}

\author{
Thieme Verlag, New York, Stuttgart, Delhi, Rio de Janeiro, 2016, EUR (D) 109,99 EUR (A) 113.10 \\ CHF 126,00, ISBN: 978-1-62623-227-3
}

\section{Pierre Kehr ${ }^{1}$}

Received: 6 May 2018 / Accepted: 20 May 2018 / Published online: 4 June 2018

(c) Springer-Verlag France SAS, part of Springer Nature 2018

Volume 7 of this important AOSpine series devoted to the treatment of the spinal affections is dedicated to the traumatic lesions of the spinal cord and its regeneration.

After a chapter on the evaluation of the medullary attack and the classification of the lesions, the role of the biomarkers serologic in the establishment of the forecast is presented, as well as the place of the MRI current and future.

The current state of the art concerning the non-operational treatment in emergency follows now.

The surgical treatment is seen under the two questions: What do we know and which must we do?

The therapy by methylprednisolone can be a valid alternative and constitutes another question which is studied in the following chapter. The place of hydrogels in repair and neuronal regeneration; the transplantation of stem cells; electric stimulation to help recovery after trauma medullary; the modern strategies of equipment, are as many enthralling chapters which supplement this book.

This Work should appear in the library of all the neurologists, neurosurgeons and rehabilitation doctors concerned with the diagnosis, the forecast and the modern treatment of the spinal cord trauma.

\section{Compliance with ethical standards}

Conflict of interest The author declares that he has no competing interests.
Pierre Kehr

Strasbourg, France 